\title{
Tumours of salivary glands in the stomatology and maxillo-facial surgery unit at the university hospital centre -Yalgado Ouédraogo
}

\author{
Mathieu Millogo ${ }^{*}$, Tarcissus Konsem ${ }^{1}$ Haréfétéguéna Bissa² ${ }^{2}$ Rasmané Béogo ${ }^{3}$, \\ Dieudonné Ouédraogo ${ }^{1}$ \\ ${ }^{1}$ Service of Stomatology and Maxillo-Facial Surgery of the University Hospital Yalgado Ouédraogo, Ouagadougou, Burkina Faso \\ ${ }^{2}$ Service of Stomatology and Maxillo-Facial Surgery of the University Hospital of Tokoin, Lomé, Togo \\ ${ }^{3}$ Service of Stomatology and Maxillo-Facial Surgery of the University Hospital Souro SANOU, Bobo-Dioulasso, Burkina Faso \\ Email: milmathieu@yahoo.fr
}

Received 20 September 2013; revised 1 November 2013; accepted 19 November 2013

Copyright (C) 2013 Mathieu Millogo et al. This is an open access article distributed under the Creative Commons Attribution License, which permits unrestricted use, distribution, and reproduction in any medium, provided the original work is properly cited.

\begin{abstract}
The aim of this study was to contribute to strengthening the efficiency in the treatment of the salivary gland tumours in the Stomatology and Maxillo-facial surgery service at the University Hospital Centre/Yalgado OUEDRAOGO of Ouagadougou. It has been a retrospective and descriptive study covering seven (7) years [January 2006-December 2012] on epidemiology and the treatment of 54 cases of the salivary glands tumours histologically confirmed. Benign tumours (non-malignant tumours were prevalent $(61.11 \%$ of cases). The annual incidences were 4.71 cases for non malignant tumours and 3 cases for malignant tumours. The average age was 34 - 45 years for non malignant tumours and 44 - 33 years for malignant ones. In both groups, the tumour was discovered lately with an average 32 - 48 months before consulting in case of non malignant tumours and 18 - 29 months for malignant tumours. The location of non malignant tumours was very often the parotid $(42.42 \%)$, under mandible gland (27.28\%). Malignant tumours very often concerned the parotid $(\mathbf{7 6 . 1 8 \%})$ and the under mandible gland $(14.29 \%)$. The histology has revealed that pleomorphic adenoma was the leading type of non-malignant tumours $(93.94 \%$ of cases) whereas carcinoma was predominant in malignant tumours (80.95\% of cases). Long term track keeping was difficult and it has been complicated by the loss of contact with some patients. The low living standard, the time wasted before consulting, limited human resources and therapeutic means constitute handicaps to the treatment in our African context.
\end{abstract}

"Corresponding author.
Keywords: Tumours; Salivary Glands; Epidemiology; Histology; Treatment

\section{INTRODUCTION}

The tumours developed at the expense of the main salivary glands (parotid, under-mandible, sub-lingual) and accessory salivary glands are relatively frequent in everyday medical practice. Indeed, according to Ansari [1], in the Republic of Iran and Boko [2] in Togo, they represent respectively $3 \%$ to $6 \%$ of all tumours of the head and neck and $17.19 \%$ of Oto-Rhino-laryngology sphere.

Salivary gland tumours have a diverse histology, but the non-malignant forms are prevalent with pleomorphic adenoma as the leading type [3-5]. However, tumours are not rare and they remain the haunting memory for any doctor. Only anatomo-phatologic study enables to diagnose these tumours efficiently and therefore to suggest the appropriate therapeutic attitude [6].

The earlier diagnose of salivary gland tumours is the guaranty for an optimal treatment. In our under-developed African context, many difficulties are met impeding seriously diagnostic and therapeutic procedure. As a matter of fact, most patients come to consult at a very advanced stage of the disease, with very developed tumours called historic ones. Incidentally, their precariousness limits seriously diagnostic investigations and therapeutic responds. The aim of this study is to do the inventory of salivary gland tumours in our context in order to strengthen the efficiency of their treatment.

\section{PATIENTS AND METHOD}

It was a retrospective study concerning medical files of patients' suffering from tumours of salivary glands in the 
Stomatology and MaxillO-facial surgery unit at the University Hospital Centre-Yalgado OUEDRAOGO from 2006 to 2012 representing 7 years.

Our population of study was a non probabilistic and exhaustive type. The study has taken into consideration all the salivary glands tumours cases treated in the hospital service and which histology was confirmed during the period of study. We have examined patients coming for consultation and completed the sample with data from hospitalization's registers. We have also used data from surgery reports and patients' medical reports. The variables studied were epidemiologic (age, sex, profession), clinical, histological and therapeutic. Data have been analyzed with EPI INFO 3.5.1 software/French version August 2008. Statistic calculations have been done with Chi 2 of Pearson to compare different variables with an Alpha risk equal to 0.05. The test is considered as conclusive if the value of $\mathrm{P}$ is less than 0.05 . Due to our context, it was not possible to practice immuno-histochemistry investigation.

\section{RESULTS}

\subsection{Epidemiological Aspects}

During the period of study, 77 files have been recorded and 54 have been kept on the basis of inclusion criteria. This serial counted 33 non-malignant tumours and 21 malignant tumours of salivary glands. The annual incidence was 4.71 cases for non-malignant tumours and 3 cases for malignant tumours. The breaking down of patients by sex has been reported in Table 1 .

$\mathrm{Chi}^{2}$-corrected $=4.4728, \mathrm{P}=0.03444$. The relation between the sex and the type of tumours has been statistically significant $(\mathrm{P}<0.05)$.

The sex ratio of all the salivary glands tumours was at 0.86 . It was at 0.5 in non-malignant series and at 2 in malignant tumours.

The patients' average age was 39.28 with extremes of 2 and 70 years old. In the cases of non-malignant tumours, the age group of $(15-30)$ was the modal class. The average patients' age carriers of a non-malignant tumour of saliva glands were 34.45 with some extremes of 2 and 60 years. For malignant tumours, the modal class was the age group of (45 - 60).

The patients' averages age was 44.33 with extremes of 6 and 70 years old.

Table 1. Breaking down of patients by sex.

\begin{tabular}{cccc}
\hline Sex & $\begin{array}{c}\text { Non-malignant } \\
\text { tumours }\end{array}$ & $\begin{array}{c}\text { Malignant } \\
\text { tumour }\end{array}$ & Total \\
\hline Female & $22(66.67 \%)$ & $7(33.33 \%)$ & $29(53.70 \%)$ \\
Male & $11(33.33 \%)$ & $14(66.67 \%)$ & $25(46.30 \%)$ \\
Total & $33(100 \%)$ & $21(100 \%)$ & $54(100 \%)$ \\
\hline
\end{tabular}

\subsection{Clinical Aspects}

In the non-malignant tumours serial, the average consulting time was 32.48 months with extremes of 1 to 120 months. In malignant tumours cases, 18.29 months were the average time before consulting with extremes of 1 to 72 months.

Non-malignant tumours were located at the parotid (42.42\%), at under mandible gland (27.28\%), at sub lingual gland (12.12\%) at palatal gland (9.09\%) and at lips gland (9.09\%) (Figures 1 and 2). Malignant tumours were also located at salivary glands, but with a great predilection for the parotid: parotid (76.19\%) under mandible gland $(14.19 \%)$ and palate gland $(9.52 \%)$. Tissue covering the tumefaction was apparently healthy in $84.85 \%$ of non-malignant tumours, and ulcerous in $42.86 \%$ of malignant tumours The value of $\mathrm{Chi}^{2}=21.26$ and $\mathrm{P}=0.002$ (Figures 3 and $\mathbf{4}$ ).

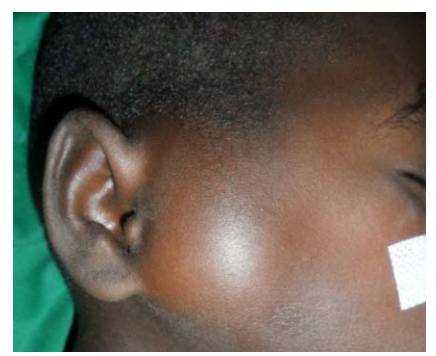

Figure 1. Pleomorphic adonoma of the parotid gland.

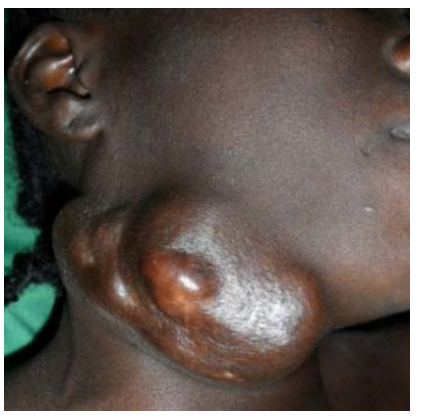

Figure 2. Under mandible gland tumour.

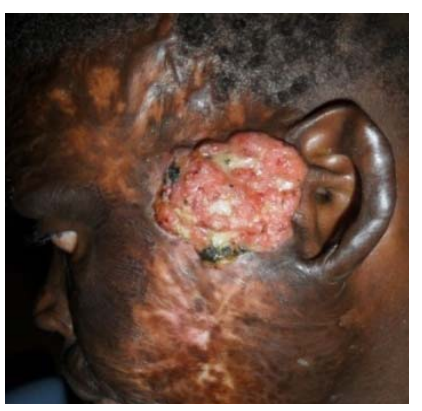

Figure 3. Carcinoma of the parotid gland on burn scars. 


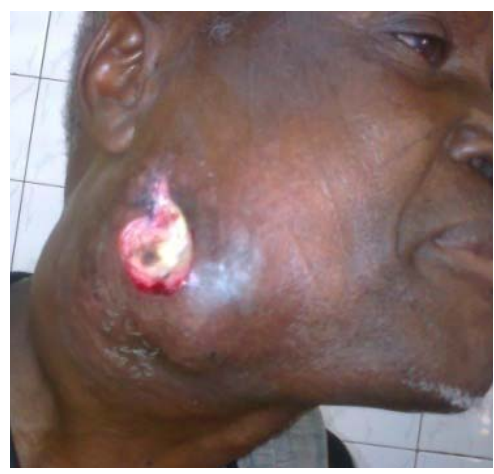

Figure 4. Parotidian sarcoma.

\subsection{Histological Aspects}

Histological types encountered have been summed up in Table 2.

The non-malignant tumours predominated with $61.11 \%$. Pleomorphic adenoma was the most frequent non-malignant tumour (93.94\% of cases).

The malignant tumours (38.89\% of cases) were dominated by carcinomas ( $80.95 \%$ of cases).

Two types of carcinoma were frequently met: the epidermoid carcinoma and the cystic adenoid carcinoma, $23.53 \%$ of cases each. Sarcomas, $19.05 \%$ of malignant tumours were as follow: 1 case of fibro-sarcoma, 1 case of lipo-sarcoma and 2 cases of non differentiated sarcoma (Figures 5-8).

The histological breaking down by age group has been represented in the Table 3.

A great proportion of patients suffering from pleomorphic adenoma (32.26\%) were found in the age group of (15 - 30). Patients suffering from carcinoma belonged to the age group of (45 - 60) representing $47.06 \%$ of cases.

\subsection{Therapeutic Aspects}

The therapeutic means were surgery and medicinal treatment. A surgical treatment has been done with all patients suffering from non-malignant tumour. It has been a tumourous extraction taking out the entire or part of the gland.

In cases of malignant tumours, the tumourous extraction required taking out the entire gland and in addition to this a lymphe node groove was associated.

Anti-cancerous chemotherapy used as adjuvant treatment to surgery has been necessary for only 3 patients. The evolution has been characterized by the transformation of pleomorphic adenoma into malignant histocystoma of the parotid with a six years step back. Moreover, 5 cases of recurrences of pleomorphic adenoma and 2 cases of recurrences of malignant tumours were noticed with a step back of 2 years. However, in 41 patients (75.93\%) were no longer in touch with medical staff with a step back of 6 years.

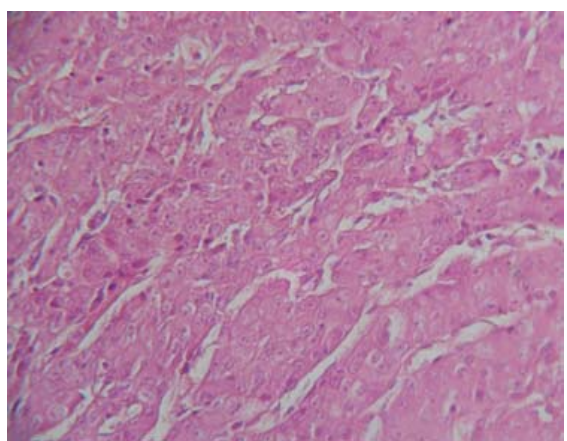

Figure 5. Microscopical aspect of oncocytary carcinoma of saliva glands.

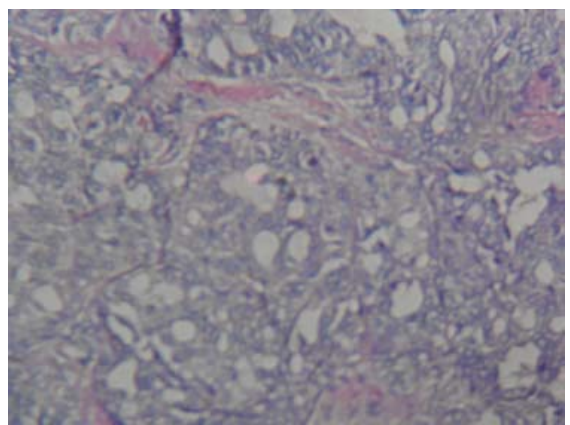

Figure 6. Microscopy of a cystic adenoid carcinoma.

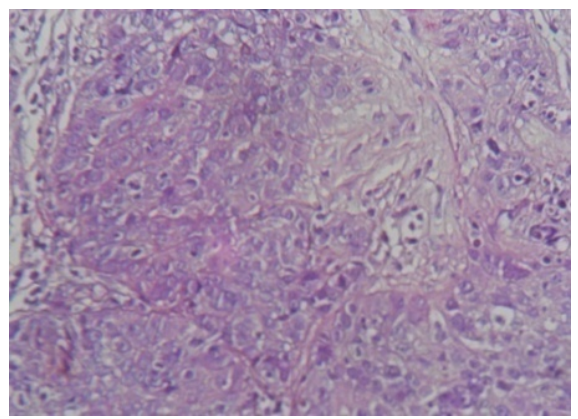

Figure 7. Microscopical aspect of epidermoid carcinoma moderately differenciated of the parotid.

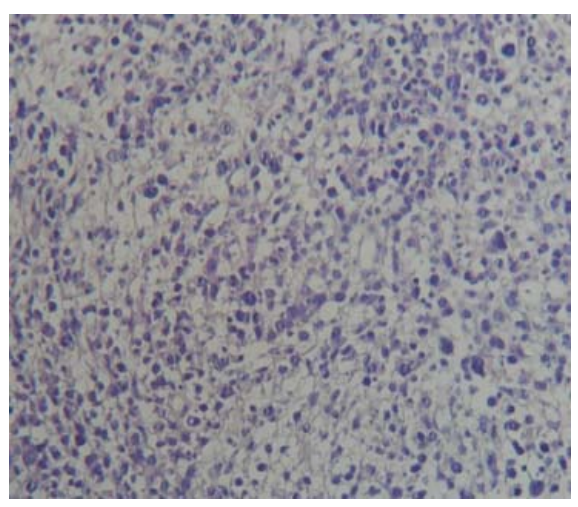

Figure 8. Microscopical aspect of a sarcoma of the parotid. 
Table 2. Breaking down of tumours according to the histological type.

\begin{tabular}{cccc}
\hline \multicolumn{2}{c}{ Histological types } & Value & Percentage \\
\hline $\begin{array}{c}\text { Non-malignant } \\
\text { tumours }\end{array}$ & Pleomorphic adenoma & 31 & 57.41 \\
\multirow{3}{*}{ Malignant tumours } & Oncosis [oncocytoma] & 2 & 3.70 \\
& Carcinoma & 17 & 31.48 \\
& Sarcoma & 4 & 7.41 \\
& TOTAL & $\mathbf{5 4}$ & $\mathbf{1 0 0}$ \\
\hline
\end{tabular}

Table 3. Distribution of histological types according to age group.

\begin{tabular}{ccccc}
\hline & $\begin{array}{c}\text { Pleomorphic } \\
\text { adenoma } \mathrm{N}^{\circ}(\%)\end{array}$ & $\begin{array}{c}\text { Oncocytoma } \\
\mathrm{N}^{\circ}(\%)\end{array}$ & $\begin{array}{c}\text { Carcinoma } \\
(\%)\end{array}$ & $\begin{array}{c}\text { Sarcoma } \\
\mathrm{N}^{\circ}(\%)\end{array}$ \\
\hline$(0-15)$ & $3(9.68)$ & $0(0)$ & $1(5.88)$ & $0(0)$ \\
$(15-30)$ & $10(32.26)$ & $2(100)$ & $1(5.88)$ & $2(50)$ \\
$(30-45)$ & $9(29.03)$ & $0(0)$ & $4(23.53)$ & $0(0)$ \\
$(45-60)$ & $8(25.81)$ & $0(0)$ & $8(47.06)$ & $1(25)$ \\
$>60$ & $1(3.22)$ & $0(0)$ & $3(17.65)$ & $1(25)$ \\
TOTAL & $31(100)$ & $2(100)$ & $17(100)$ & $4(100)$ \\
\hline
\end{tabular}

\section{DISCUSSION}

\subsection{Epidemiological Aspects}

Tumourous pathology of salivary glands is relatively frequent $[2,5]$. In a period of seven years, we have recorded 54 cases confirmed by the histology. We think however that these figures are far from the reality due to the under notification of cases. In our context characterized by poverty and ignorance of the population, a great number of patients don't do anatomo-pathologic check and another important number do not go to hospital, having preference for traditional medicine. In fact after surgery, many patients could not afford to do the anatomo-pathologic checking of the operated part. The histological extempore per operative checking was not available. In addition to this, cancers register in Burkina is not functional and it does not permit to record all the malignant tumours cases. The 54 salivary glands tumours were composed of 21 malignant tumours (38.89\% of cases) and 33 non-malignant cases (61.11\% of cases).

The prevalence of non-malignant salivary glands tumours in comparison to malignant tumours is reported by most of the authors: Ehsen [5] in Tunisia (88\% of nonmalignant tumours and $12 \%$ of malignant tumours), Ochida [7] in Nigeria (56.5\% of non-malignant tumours and $43.6 \%$ of malignant tumours). We have noticed a prevalence of female patients $53.70 \%$ suffering from non-malignant tumours of salivary gland. The sex-ratio was 0.86 . Similar results have been observed by most of the authors [2,8-11].

In the malignant tumours serial, there was a prevalence of male patients with a sex ratio of 2 . There was a significant statistic relation between the sex and the nature of the tumour (the $\mathrm{Chi}^{2}$-corrected $=4.4728, \mathrm{P}=$ $0.03444)$. The male prevalence being noticed in malignant tumours and female predominance in non-malignant tumours salivary glands. In our society in fact, men are more active and seem more exposed to different risk factors (alcohol, tobacco, irradiations, etc.) responsible for malignant tumours. Besides, men tended less to visit doctors in absence of evident symptoms, also because of socio professional constraints and ignorance.

As far as women are concerned, their esthetical preoccupation obliged them to go earlier to consultation than men as soon as they notice a facial and cervical tumefaction.

In the non-malignant tumours series, the age group of (15 - 30) was the modal class. The average year of the appearance of non-malignant tumours of salivary glands was 44 , 33. Non malignant tumours would appear at any age, but with high frequency as far as young persons are concerned [4,11]. In the malignant tumors serial, the modal class was the age group (45 - 60) years. The average of appearance of malignant tumours of saliva glands was 44.33 years. Classically malignant tumors are frequent with aged subject, with risk factors such as tobacco, alcohol and the absence of month and dental hygiene $[4,5,11]$.

\subsection{Clinical Aspects}

The time before consulting was relatively long in these series and most of the patients have often come with tumours already in evolution. Indeed socio-cultural beliefs and the difficulties to afford hospital cures, in addition to the geographical distance of most hospital centers oblige patients to resort to traditional medicine before coming in a modern one. We also have the lack of qualified medical staff.

All salivary glands can be the location of a tumour (non-malignant or malignant) but with prevalence at parotid. The prevalence of non malignant and malignant tumors of salivary gland at the parotid can be explained by the fact that this it is the biggest one and the most functional of salivary glands [12-15].

\subsection{Anatomo-Pathologic Aspects}

Non-malignant tumors represent $61.11 \%$ of all tumors of our series.

The pleomorphic adenoma was the most frequent tumour (93.94\% of non malignant tumours). This prevalence of pleomorphic adenoma has been found by all the authors who dealt with the question. Ehsen B.B. in Tunisia [5] and Edda A.M.V. in Ouganda [4] have respectively reported among tumors of their series $81.9 \%$, 88\% and $74.8 \%$ of pleomorphic adenoma. The frequency of 
the pleomorphic adenoma among non malignant tumors of salivary glands could be explained by the cellular diversity of salivary glandular tissue. The pleomorphic adenoma is indeed a mixed tumor. Its microscopy shows epithelial and myoepithelial cells in an abundant stroma with some chondroma or myxoid areas [2,5,16,17]. Malignant tumours represented $38.89 \%$ of all the tumours (80.95\% of carcinomas and $19.05 \%$ of sarcomas). The epithelial nature predominating in salivary glands cells could explain the predominance of carcinoma $[18,19]$.

We have noticed in our series 9 different types of carcinomas dominated by the epidermoid carcinoma (23\%, $53 \%$ ) and adenoid cystic carcinoma (23.53\%).

This histological diversity among malignant tumours of salivary glands could be explained by the diversified characteristic of salivary glands cells (epithelial intermediaries, acinous, oncosis, malpighian). There seems to be a general agreement on the prevalence of carcinomas among malignant tumours of salivary glands and on the histological diversity of carcinomas. However, no histological form among carcinomas of salivary glands has been considered as leading type of the file [5,7,18-20].

Sarcomas were less frequent (19.05\% of malignant tumours), but with also varied histologic types. This concerns rare nesenchymatous tumours appearing at all age and representing nearly $1 \%$ of all cancers $[8,12,15,17$, 20].

\subsection{Therapeutic Aspects}

The treatment of non malignant tumours of salivary glands is exclusively surgical [6].

The treatment of malignant tumours of salivary glands is multidisciplinary. It combines oncology, surgery, radiotherapy and psychology. It takes into consideration the histopathology of the tumour, its state of evolution, its location, the availability of medical platform and the patient. Chemotherapy and radiotherapy are often used to complete surgery in the therapeutic protocol. The radiotherapy was not available in our context. In addition, the immuno-histochemistry could not be done, which has certainly limited the choice of the drugs in the chemotherapy. The particular case is the one of parotid gland. As a matter of fact, therapeutic indication depends on the location, the volume of the tumour, the age of the patient, but also the results of the histological examination extempore and the infiltration of adjacent structures by the tumour $[6,10,18]$. An evoluated malignant tumour will require a surgical extraction of the gland (partial or entire), extended to adjacent structures (facial nerves, muscular plan). The histological type and grade of malignant tumour as well as its clinical stage will necessitate a lymph node groove. Radiotherapy in association with surgery improves the prognostic of treated tumours and decreases the rate of local and regional recurrence [18].

The evolution of salivary glands tumours in our context has been characterized by recurrences (5 cases of pleomorphic adenomas and 25 cases of malignant tumours) and a malignant transformation of plesiomorphic adonema. We think however that there is an under notification of recurrent cases in our study due to the difficulty to follow patients in long term. The great number of patients who did not keep in touch with medical staff can be a justification. Recurrences are often linked to an incomplete resection of the initial tumour, especially in case of exo facial parotidectomy. Generally, the pleomorphic adenoma has a high tendency to recurrence $[3,8]$.

\section{CONCLUSION}

The pathology of salivary glands tumours is relatively frequent but less known by our population. An accurate diagnosis rests upon the histological examination. The very concern with salivary gland tumours in our context is their treatment. As a matter of fact, most patients consult lately or wander about because of ignorance or socio-cultural beliefs. The difficulties at the therapeutic level are particularly due to an insufficiency of qualified human resources, but also because of the medical platform under acceptable standard. All these situations do not permit an adequate treatment. In addition to this, we have the ignorance of the population and the precariousness.

\section{REFERENCES}

[1] Ansari, M.H. (2007) Salivary gland tumours in an Iranian population: A retrospective study of 130 cases. Journal of Oral and Maxillofacial Surgery, 65, 2187-2194.

http://dx.doi.org/10.1016/j.joms.2006.11.025

[2] Boko, E., Napo-Koura, G., Kpemissi, E. and Boko-Bessi, L. (2004) Tumours of secondary salivary glands: Epidemiologic and histological aspects. Journal of Oto-RhinoLaryngology, 125, 233-237.

[3] Akkari, K., Chnititir, S. and Sethom, A. (2007) Parotid tumours: About 43 cases. Tunisian Journal of Oto-RhinoLaryngology, 18, 29-33.

[4] Edda, A.M.V. (2004) Salivary gland tumours in Uganda: Clinical pathological of 268 cases. African Health Sciences, 4, 15-23.

[5] Ehsen, B.B., Malek, F. and Olfa, K. (2010) Salivary gland tumours; histological and epidemiologic study of a 180 cases serial. Tunisia Medical Journal, 88, 240-244.

[6] Bensadoun, R., Dassonville, O. and Rousmans, S. (2008) 2008 update of standars, options: Recommendations for management of patients with salivary gland malignant tumors. Bulletin du Cancer, 95, 735-749.

[7] Ochicha, O., Malami, S., Aminu, M. and Akinfenwa, A. (2009) A histopathologic study of salivary gland tumors in Kano, Northen Nigeria. Indian Journal of Pathology 
and Microbiology, 52, 473-476. http://dx.doi.org/10.4103/0377-4929.56121

[8] Flavia, A.O., Eliza, C.B.D. and Claudia, T.T. (2009) Salivary gland tumour: A revew of 599 cases in a Brazilian population. Head and Neck Pathology, 3, 271-275.

[9] Jansisyanont, P. and Blanchaert, R.H. (2002) Salivary glands tumours of the oral cavity: About 80 cases. International Journal of Oral and Maxillofacial Surgery, 31, 257-261. http://dx.doi.org/10.1054/ijom.2002.0223

[10] Ouoba, K., Dao, M., Sakande, B., Kabre, M., Cisse, R. and Ouedraogo, I. (1998) Salivary glands tumours: About 48 cases opereted. Burkina Medical Journal, 2, 55-59.

[11] Solange, S.L., Andréa, F.S., Rivadado, F., Batista, A. and Roseana, A.F. (2005) Epidemiologic profile of salivary gland neoplasms: Analysis of 245 cases. Revista Brasileira de Otorrinolaringologia, 71, 335-340.

[12] Sadetzki, S. (2007) Cellular phone use and risk of benign and malignant parotid gland tumors: A nationwide casecontrol study. American Journal of Epidemiology, 167, 457-467. http://dx.doi.org/10.1093/aje/kwm325

[13] Fonseca, F.P., de Vasconcelos, C.M. and de Almeida, O.P. (2012) Clinicopathologic analysis of 493 cases of salivary gland tumors in a Southern Brazilian population. Oral Surgery, Oral Medicine, Oral Pathology and Oral Radiology, 114, 230-239.

http://dx.doi.org/10.1016/j.000o.2012.04.008

[14] Mahmoud, S., Mohamed, J.A., Negar, A., Bijan, K., Basir,
H. and Amir, A. (2011) Maxillo-facial salivary glands tumours: A retrospective study about 130 cases in south iran population. Pathology Research International, 87, 934-938.

[15] Moatemri, R., Belajouza, H. and Farroukh, U. (2008) Epidemiologic profile of salivary glands tumours at a Tunisian academic hospital: About 156 cases. Stomatology and Maxillo-Facial Surgery Journal, A, 109, 148-152.

[16] Oukabli, M., Boudhas, A. and Setti, K. (2012) Salivary glands tumours: An histological study about 105 cases. African Cancer Journal, A, 4, 30-36.

[17] Toure, S., Sonko, L., Diallo, B., Diop, A., Diouf, R. and Diop, E.M. (2005) Epidemiologic profile of oral cavity cancers in Senegal. Revue de Stomatologie et de Chirurgie Maxillo-Faciale, 106, 17-26.

[18] Halimi, P., Gardner, M. and Petit, F. (2005) Salivary glands tumours. Cancer/Radiothérapie, 9, 251-260. http://dx.doi.org/10.1016/j.canrad.2005.06.003

[19] Kokemuller, H., Bruggemann, N., Brachvogel, P. and Eckardt, A. (2004) Epithelial Malignant tumours of Salivary glands. A twenty years clinical study. Mund Kiefer Gesichtschir, 8, 191-201.

[20] Védrine, P.O., Toussaint, B., Lapeyre, M., Coffinet, L., Sommelet, D. and Jankowski, R. (2004) Children salivary glands cancers. Annales d Oto-Laryngologie et de Chirurgie Cervico-Faciale (Masson, Paris), 121, 257-265. 